Paidéia, 2003, 13(25), 85-96

\title{
GRUPO DE SALA DE ESPERA: SENTIDOS DO ENVELHECIMENTO HUMANO'
}

\author{
Cesar Sandoval Moreira $J$ r. \\ Marisa Japur ${ }^{2}$ \\ FFCLRP - Universidade de São Paulo
}

RESUMO: Este trabalho parte da consideração do envelhecimento humano como experiência heterogênea. Busca pôr em diálogo o grupo de sala de espera, recorrendo ao construcionismo social, para descrevê-lo como prática discursiva. Problematizando essa modalidade de intervenção psicológica, nesse estudo objetivamos descrever o processo de produção de sentidos sobre o envelhecimento humano nesse contexto. Dez grupos de sala de espera, gravados e transcritos, foram pré-analisados favorecendo a escolha de um deles para análise extensiva. Essa análise apontou que, nesse processo conversacional, a vivência do envelhecimento como experiência individual vai sendo paulatinamente reconstruída pelos interlocutores como de natureza sócio-interacional, apontando para posições mais ativas na produção de qualidade de vida no envelhecimento. Assim, os participantes em co-autoria, falando de seus cotidianos, abrem possibilidades de novas descrições sobre si mesmos enquanto pessoas idosas, nesse contexto interativo.

Palavras-chave: prática grupal; envelhecimento humano; construcionismo social

\section{WAITTING ROON GROUP: HUMAN AGING MEANING'S}

ABSTRACTS: This research question the human aging while universal experience. Using the social construcionism, the waiting room group is understood as a discursive production, having the language as a main point of social practices and focalizing a relational perspective in the producing process of the world meanings. Thinking about this psychological intervention, we have the purpose of describing the meaning production process about the human aging in this context. Ten waiting room groups, recorded and transcribed, were analyzed, what made possible the selection of one of them for extensive analyses. Their analysis show that in this conversation the aging experience like an individual experience is being changed by the speakers as social interaction, pointing to actives positions on healthy life quality aging production. The speakers construct several meanings about aging, talk about themselves in their daily relationships, creating the possibility for new descriptions about themselves as elders in this interactive context.

Key words: group experiences; human aging; social construcionism

O envelhecimento humano se tornou uma das grandes preocupações sociais do momento e, conforme apontado por Camarano e cols. (2000), dentre os diversos fatores que contribuem para tal está o fenômeno da longevidade.

A progressiva constituição de populações cada vez mais maduras concorre para destacar o envelhe-

\footnotetext{
'Artigo recebido para publicação em 19/07/02; aceito em 03/04/ 03.

2 Endereço para correspondência: Marisa Japur, Departamento de Psicologia e Educação, Faculdade de Filosofia, Ciências e Letras de Ribeirão Preto, USP, Av. Bandeirantes, 3900, Monte Alegre, Ribeirão Preto, SP, Cep 14040-901, E-mail: mjapur@ffclrp.usp.br
}

cimento humano na pauta dos interesses científicos e sociais, dotando-o de crescente visibilidade, e favorecendo a configuração e legitimação de instâncias discursivas que levam a sociedade a se articular em torno do enfrentamento das questóes colocadas pelo envelhecimento populacional. (Debert, 1999).

Compreender as formas de gestão da velhice na contemporaneidade traz como exigência, segundo Debert (1999), um engajamento em direção à elucidação de como os múltiplos discursos sociais atuam na construção social do envelhecimento.

Remetendo-nos a Gergen (1997), em suas des- 


\section{Cesar Sandoval Moreira Jr}

crições dos processos de recodificação das produções do senso comum segundo a lógica da ciência, e de tecnologização da sociedade, quando corpos de conhecimento científico lhe são repassados, numa estrita interdependência entre os discursos científicos e culturais, traremos alguns apontamentos relativos à construção social do envelhecimento humano.

Além de também contribuir com a visibilidade e legitimação da velhice como proeminente questão social, a Gerontologia tem, segundo Lopes (2000), assumido a gerência do envelhecimento, constituindo-o ainda como objeto de saber e profissionalização.

Aludindo especificamente à constituição do discurso psicológico no campo do envelhecimento humano, Neri (1993) considerou que o mesmo tem sido produzido com base num modelo deficitário do desenvolvimento na vida adulta, a partir dos pressupostos da ideologia da velhice. Se em seu início a Psicologia do Desenvolvimento se resumia a campo praticamente sobreposto ao da Psicologia Infantil, a autora salientou que até bem recentemente a literatura em Psicologia do Desenvolvimento vinha considerando o desenvolvimento apenas em termos de ganhos, num movimento unidirecional e seqüencial rumo à maturidade. Seu foco de interesse direcionavase basicamente aos periodos da infância, da adolescência, e às questões clínicas da vida adulta, enfatizande, neste último caso, limitações e perdas em detrimento de potencialidades. Num contexto de valorização da produtividade e do vir-a-ser, em que a perspectiva de ganhos decorrentes do potencial de crescimento da infância ajustava-se sob medida, desenvolvimento e envelhecimento eram considerados termos antagônicos e incompatíveis. Fundada nas premissas da ideologia da velhice e tendo por raiz o modelo deficitário do desenvolvimento na vida adulta, as ciências em geral e a Psicologia em particular produziam, validavam e co-construiam as características de involução e estagnação de desenvolvimento na velhice, demarcando-a como período de perdas, disfuncionalidades, afastamentos e deteriorações.

Remetendo-nos ainda a alguns dos sentidos do envelhecimento, gerados no tempo histórico (Beauvoir, 1990; Costa, 1998; Lima, 1996; Minois, 1997), podemos considerar que a velhice tem também sido cientificamente construída a partir de duas perspectivas hegemônicas: como período de perdas, involução, estagnação, falta de engajamento, disfuncionalidades, doenças, deterioração, vulnerabilidade e proximidade com a morte, ou como período de aprendizagem, atividade, sabedoria, liberdade, despreocupação e prazer.

Em ambas as perspectivas, em detrimento dos fatores sócio-históricos, a velhice vem sendo produzida sobretudo como atributo e responsabilidade individuais (Neri, 1993).

Uma característica recente no campo da Gerontologia refere-se, segundo Debert (1999), às tentativas da desnaturalização do envelhecimento humano como experiência e processo homogêneos e universais, com discursos voltados para a qualidade de vida, sendo ambas, velhice e qualidade de vida, produzidas como resultantes de interações interpessoais em contextos em transformação. Há, segundo a autora, um consenso quanto às inúmeras transformações na experiência do envelhecimento ao longo do século $\mathrm{XX}$, resultando na mudança de paradigma sobre a velhice, e numa maior variedade de possibilidades e alternativas de modelos.

$\mathrm{Na}$ medida que o envelhecimento possa ser considerado como uma construção social, no sentido em que as pessoas vivem, se desenvolvem e se constroem a partir dos parâmetros, limites e possibilidades da própria sociedade e dos sentidos socialmente construídos sobre o mesmo, emerge como necessidade a desnaturalização de algumas das concepções hegemônicas que circulam no nosso dia-a-dia e que acabam por embasar nossa compreensão sobre a velhice. Nesta perspectiva, o envelhecimento, a maneira como o produzimos, são construções sociais negociadas, e os conceitos de velhice, terceira idade, idoso e derivativos, representam categorias construídas socialmente, sob cujo rótulo e abrangência estão postas múltiplas formas de vivenciar o envelhecimento e toda singularidade possível (Costa, 1998).

Entre decorrências da transição demográficoepidemiológica, da revisão dos paradigmas sobre a velhice, da incorporação de fatores sócio-históricoculturais, e do recente protagonismo dos idosos como atores sociais, podemos também destacar recentes e profundas alterações no perfil das políticas públicas no Brasil (Lima, 1996).

Nas décadas de oitenta e noventa do século $\mathrm{XX}$, por exemplo, delinearam-se algumas diretrizes 
básicas norteadoras das novas propostas de atenção à saúde da população idosa.

Em 1994, a elaboração da Política Nacional do Idoso (Brasil, MJ/SNDH1998) contemplou os princípios centrais da Reforma Sanitária brasileira, entre os quais podemos destacar a ênfase na criação de dispositivos sanitários alternativos ao modelo asilar, e na necessidade de produção de novas práticas sócioinstitucionais.

Em relação a este último aspecto, Lo Bianco, Bastos, Nunes e Silva (1994), referindo-se especificamente à inserção da Psicologia no contexto da saúde pública, salientaram um crescente privilégio às ações de caráter coletivo, onde, com base na necessidade da construção de uma práxis. inovadora e crítica, os dispositivos grupais assumiram caráter central na construção do trabalho interdisciplinar junto às populações usuárias dos serviços de saúde, inclusive a idosa.

Ainda que produzidas como resposta à perspectiva individualista e ao modelo de atenção individual no contexto da atenção em saúde, Barros (1994) considerou que as práticas grupais tão em voga nos diversos dispositivos sócio-institucionais estão predominantemente informadas por esses mesmos princípios. Segundo a autora, quer seja por questões mercadologicas, técnicas ou institucionais, sua proliferação tem-se dado com base na pressuposição de que essa opção de trabalho seja inerentemente mais adequada, independentemente das formas de produção e das perspectivas de sustentação.

Entre as noções hegemônicas grupalistas, podemos destacar a noção de grupo como totalidade, com identidade própria, compondo unidade intermediária na relação indivíduo-sociedade, onde a entidade grupo representa algo mais / além dos elementos que o compõem. A noção de setting pressupõe a delimitação de um cenário legitimado dos processos grupais, implicando em limites entre o grupo e o não-grupo, e o número restrito e constante de pessoas veio a se configurar como um componente do enquadre de trabalho. $O$ objeto grupo tem sido, em coerência com o contexto modernista de sua emergência, construído como objeto já dado, atravessado por processos universais, onde os aspectos teóricos assumem primazia sobre a experiência nas relações (Barros, 1994).

Outro aspecto a ser considerado nos desen- volvimentos grupalistas no Brasil diz respeito, segundo Pérez (1997), ao impacto do movimento da dinâmica de grupos, com forte influência das produções norte-americanas, inglesas e francesas na institucionalização das práticas grupais nos diversos dispositivos sócio-institucionais, e um escasso desenvolvimento de aportes teórico-metodológicos contextualizados. $\mathrm{O}$ autor apontou como outro fator que repercute consideravelmente no desenvolvimento do campo grupal, um relativo descaso por parte da Psicologia Social em relação ao objeto grupo, redundando em maiores desenvolvimentos sobretudo a partir de perspectivas clínicas clássicas.

Novas configurações grupalistas têm emergido, segundo Lane (1994), da articulação entre intervenções institucionais e produções teóricas, quando com a superação da dicotomia indivíduo-grupo, procederam-se reflexões sobre algumas de suas amarras teórico-conceituais. Com a ênfase na noção de processo grupal, este passou, segundo a autora, a ser construído como espaço de reflexão / interação / multiplicidade, como devir produzido na interação.

$\mathrm{Na}$ análise da produção científica relativa a uma dessas novas configurações, especificamente o grupo de sala de espera, encontramos grande variação no uso dos termos grupo de sala de espera ou grupo de espera. Muitos trabalhos referem-se a dispositivos de eliminação de filas de espera, agilização de triagens e encaminhamentos na forma de grupos fechados de espera para psicoterapia (Neme \& Pícaro, 1992; Schouri \& Szajnbock, 1993), ou a intervenções de caráter informativo, num enfoque educativo e/ou de preparação para o tratamento no contexto da sala de espera (Poulsen \& Jacobsen, 1994; Zaspe, Margall, Otano, Perochena \& Asian, 1997). Ainda que estudos sugiram potencialidades de intervenções em salas de espera (Lledo \& cols, 1995), podemos apontar a escassez de estudos em que elas estejam referidas às interações entre os participantes.

Partindo da desnaturalização do objeto grupo, tal como hegemonicamente construído nos modelos grupalistas clássicos, o grupo de sala de espera, aqui referido, vem sendo produzido no cotidiano de uma instituição publica de saúde voltada à atenção da população idosa. Está referido a uma proposta de 'conversar junto' feita pelo psicólogo de um Ambulatório 


\section{Cesar Sandoval Moreira $J r$}

de Geriatria, aos pacientes e acompanhantes na sala de espera, visando potencializar um espaço de interação já existente na instituição com vistas à promoção de saúde (Moreira Jr., 2001).

Entre as especificidades desse grupo, destacamos: a composição flutuante, com um fluxo indefinido de entrada e saída de participantes conforme a realização das consultas e o movimento institucional; o espaço aberto, a sala de espera da instituição; o redimensionamento da questão da demanda, uma vez que sua população alvo não está, em geral, na instituição em busca especificamente desse atendimento; sua heterogeneidade em potencial, com usuários e acompanhantes, participando tanto pela primeira vez como com participações anteriores. (Moreira Jr., 2001)

Essa prática vem sendo produzida a partir de uma perspectiva construcionista social, remetendo, então, a compreensão do grupo de sala de espera no ambulatório de geriatria a um processo de conversar potencialmente fértil em construções polissêmicas sobre o envelhecimento humano.

Partindo dessa proposta de compreender o grupo de sala de espera como contexto de produção de sentidos, esse estudo tem por objetivo descrever o processo de produção de sentidos sobre o envelhecimento humano, visando contribuir com a descrição dessa prática como uma modalidade de intervenção psicológica.

\section{Método}

Adotamos nesse estudo, a perspectiva construcionista social sobre a produção do conhecimento. Nesta perspectiva, ele é concebido como uma construção social, relativa e dependente das práticas e contextos sócio-históricos, o que problematiza tanto as possibilidades de acesso a um universal já dado, quanto as garantias fundamentais da ciência. Todas as formas de conhecer, inclusive a ciência, produzem versões sobre o mundo e sua construção através dessas versões.

Nessa posição epistemológica, há um reenquadramento dos critérios de cientificidade, em que o rigor passa a se referir à explicitação dos procedimentos metodológicos e dos passos do investigador no seu processo de produção de sentidos. Assim, na produção científica, a legitimidade se articula à visibilidade de seus processos de produção (Spink \& Menegon, 1999).

O construcionismo social enfatizando a dimensão performática da linguagem focaliza a interação, as práticas sociais. Ele compreende que é da linguagem em uso, nos múltiplos intercâmbios sociais, que derivam possibilidades de ação e de construção ativa do mundo e de si mesmo (Spink \& Frezza, 1999).

Considerando a linguagem como prática social, Spink e Medrado (1999) situam as condições de produção de sentido na articulação entre o tempo histórico (onde são forjados os conteúdos culturais discursivos de uma época), o tempo vivido (da ressignificação das construções históricas nos processos de socialização ao longo do curso de vida), e o tempo curto (tempo da interanimação dialógica no aqui-e-agora) Assim, a partir dos dispositivos lingüísticos socialmente legitimados opera-se a produção cotidiana de sentidos.

\section{Procedimentos de Constituição do Corpus}

Esta pesquisa foi desenvolvida respeitando-se as normas éticas para pesquisa com seres humanos (Brasil/MS, 1997) tendo seu projeto sido aprovado por um Comitê de Ética em Pesquisa vinculado ao CONEP. Foram gravados dez grupos de sala de espera, ao ritmo de um por semana, durante dez semanas consecutivas. Os participantes foram informados da gravação, da finalidade de estudo em relação à mesma, do caráter voluntário da participação, e do sigilo em relação ao material produzido e às suas identidades. Uma colaboradora registrou os grupos, focalizando as trocas dos turnos de falas, a movimentação e as interações. Observações referentes aos grupos foram registradas pelo pesquisador ao longo de todo o período da pesquisa.

\section{Procedimentos de Análise do Corpus}

O primeiro passo da análise consistiu da transcrição integral, pelo pesquisador, dos dez grupos gravados, acrescidos das observações realizadas pela colaboradora e das anotações do pesquisador. O passo seguinte çonsistiu na leitura flutuante e sucessiva das transcrições abarcando cada grupo em sua toda sua sequiência temporal e buscando descrevê-los quanto 
às construções e transformações dos sentidos sobre o envelhecimento humano.

Escolhemos um grupo específico para descrever o processo de produção de sentidos. A escolha recaiu em um grupo, fértil em metáforas para a tematização pretendida, que teve início com 10 pessoas, sendo 02 usuários, 05 usuárias, 01 acompanhante, o coordenador e a colaboradora, e terminou após 55 minutos, com 05 participantes - 01 usuário, 02 usuárias, o coordenador e a colaboradora.

Focalizando o processo dialógico no aqui-agora grupal e buscando produzir uma inteligibilidade sobre os sentidos construídos na análise desse grupo, delimitamos a conversa do grupo em cinco momentos: Um Corpo que Envelhece, Com quem Contar, A Familia Assume a Centralidade, Quando a Família Fracassa, e O que Ainda Resta de Vida.

\section{Análise e Discussão}

\section{Do 'corpo que envelhece' ao 'tempo que ainda resta'}

O coordenador iniciou a conversa no grupo convidando os participantes a dialogarem sobre como está a vida, como estão vivendo. Alguns teceram breves comentários, outros sorriram, e seu João inaugurou, com uma metáfora, o que construímos como um primeiro momento do grupo.

\section{Momento 1: Um Corpo que Envelhece}

João- (...) nós começa com gatinho, e se lerdá acaba no gatinho outra veiz, nenê!(...) a pessoa idosa...igual nós (...) vai voltando. Se lerdá, ele volta de gatinho outra vez!

A partir dessa metáfora disparadora da conversa no grupo, o envelhecimento é produzido por seu João como período de perdas, declínio, retrocesso, infantilização, processo natural e inevitável, produto das marcas indeléveis das ações do tempo no corpo, implicando os participantes-pessoa-idosa-igual-nós.

Em coerência com as descrições científicas de envelhecimento secundário - referente às mudanças deletérias decorrentes do aumento da idade, e envelhecimento terciário - período de declínio terminal da velhice avançada que resulta na morte (Neri \& Cachioni, 1999), os participantes, inseridos no contexto da saúde, se co-constróem como idosos em franca decadência corporal. Tratam-se também, recorrendo-se aos trabalhos de Costa (1998), Lima (1996), Beauvoir (1990) e Minois (1987), de sentidos gerados no tempo histórico, que compõem repertórios interpretativos sobre o envelhecimento e fornecem as bases para as produções discursivas dos participantes, ainda que se abra a perspectiva de um não lerdar.

O sentido de não lerdar vai sendo inicialmente construído na conversa como necessidade de busca de cuidados específicos no campo da atenção em saúde.

João - (...) trata, trata...um dia manda uma perna, outro um braço, outro dia é uma coisa, outro dia é outra, né! (ri) A idade vai...

Tiana - Eu acho só que a gente não deve se entregar, né! (...) a gente deve lutar...

Joaquim - (...) nós vai lutano (...) 'ô, mais essa árovre agora secou! Era uma árvore tão bonita, molhada de olhar"...assim é nós, num é?

Ele é construído por seu João como tratar, referindo-se à busca de cuidados médicos para retardar ou amenizar o processo de envelhecimento, preocupação apontada por Lopes (2000) como central da medicina ao longo do processo histórico. Dona Tiana reconstrói o não lerdá como não-entregá, lutá, e seu Joaquim presentifica o sentido de não lerdá remetido a cuidados inócuos e paliativos que os participantes-árvores-secando devem buscar no contexto da atenção formal em saúde, ante a inexorabilidade do declínio físico-morte.

Dona Gertrudes passa a considerar e a descrever os impactos do envelhecimento corporal, até agora atrelados ao contexto da atenção formal médica em saúde, no âmbito dos relacionamentos familiares. 
90 Cesar Sandoval Moreira Jr

Gertrudes- E, agora esses dia eu machuquei o braço (...) minha menina tá nervosa comigo (...) "que é isso, mãe, a senhora tá se entregando! Reage!" (...) tô com medo de andar (...) fiquei assim (...) num tô aguentano muito as mão, né! (...)

Tiana- Lutar (...) num pode entregar (...) num ter medo de abrir, ver a claridade, de sair na rua! Não! Vamo levantar a cabeça prá cima, vamo! (...)'

O tema envelhecimento, nesse início da conversa, é construído a partir da dimensão da corporeidade, e, nesse sentido, as possibilidades de reação, de não descuidar, são restritas ao âmbito da saúde, e, de acordo com a descrição de dona Gertrudes, praticamente inexistentes nos relacionamentos familiares intergeracionais. Dona Tiana instaura uma tensão lutar $x$ se entregar também no âmbito dos relacionamentos familiares, reconfigurando as possibilidades de reação nas vivências cotidianas. Enquanto não lerdar / lutar é construído como possibilidade de enfrentamento, de continuidade de desenvolvimento e de busca, lerdar / se entregar é construído como sucumbir ao medo, prenúncio de declínio. Quer seja no contexto da saúde, quer no contexto das relações sociais dos participantes, o envelhecimento é produzido a partir de uma perspectiva individualizante, e as possibilidades de reação, como referidas a atitudes individuais dos mesmos.

Estes passam, então, a considerar implicações e conseqüências das relações no aqui-agora grupal e nos relacionamentos familiares do tempo vivido para o envelhecimento, articulando-se em torno da questão referente a com quem podem contar nesse processo que vivenciam.

\section{Momento 2: Com Quem Contar?}

Guilherma- (...) a gente trata uma roseira (...) se nóis deixa de mão (...) Ela morre, né! Nóis tem que tá regando (...) Se todos nós pensar igual ele pensou (...) Já se torna abaixo, né! Vamo prá trás! (...) nós tem que ir prá frente! (...) subir na vida (...) Com todos nossos semelhantes, né! (...)
Na conversa do grupo vão emergindo narrativas progressivas que levam para cima e para frente, possibilidade de luta e de continuidade do desenvolvimento, e narrativas regressivas que levam para baixo e para trás, prenúncio de entrega e declínio (Gergen, 1997), e os sentidos do envelhecimento são reconfigurados à esfera das atitudes, vivências e relacionamentos sociais dos interlocutores. As possibilidades descritivas parecem, até então, articuladas a um interjogo entre duas tendências hegemônicas apontadas por Debert (1999). As descrições produzidas têm por referência ou os estereótipos clássicos da velhice, ou a noção de velhice como atividade, criatividade, autonomia, e busca de respostas originais aos desafios cotidianos, sob a perspectiva de prazer e satisfação pessoal. Dona Guilherma traz, com sua narrativa, para a arena grupal, a proposta de que os interlocutores, grupo de semelhantes, se envolvam na tarefa de entre-apoio, constituindo-se num coletivo que se rega.

Com essa proposta, com referência à tensão lutar $x$ se entregar nos relacionamentos familiares, instaura-se então também um campo de tensões no espaço de interlocução grupal, entre Tiana e Gertrudes. As diversas maneiras como as interlocutoras constroem-se nos relacionamentos familiares do tempo vivido, implicam em diferentes posicionamentos no aqui-agora grupal.

Tiana- (...) a minha filha fala assim, "mãe, a senhora só sabe falar não!" (...) isso num é orgulho! (...)é uma força que a gente tem com Deus!

Gertrudes- (...) algumas vezes, a senhora deve fazer a vontade dela, prá ela ficar alegre, a senhora come com ela! Né!

Tiana- Sabe o que que eu acho, filha? (...) nós põe mais alegria na nossa filha (...) de que se nós se entregar! (...)

Gertrudes- Não, mas de domingo ela fala, "mãe, hoje a senhora (...) vem almoçar!"... é bom demais (...) Às vezes nós trocamos misturas (...) 
Grupo de Sala de Espera 91

O campo grupal é transformado em arena de conflitos. Dona Tiana-independente-autônoma justifica seu auto-cuidado como força que tem em Deus. Dona Gertrudes propõe que dona Tiana deixe de ser tão egoísta, sugerindo que sendo assim como ela é, acaba deixando sua filha triste. Dona Tiana interrompe e desqualifica dona Gertrudes-que-se-entrega-eque-assim-deixa-a-filha-triste chamando-a de filha. Dona Gertrudes-que-pode-desfrutar-o-que-a-filhaoferece, fragilizada no início da conversa, se reconstrói como quem pode trocar e desfrutar nos relacionamentos familiares. Nessa disputa, as interlocutoras falam a partir das vozes maternas responsáveis pela felicidade/infelicidade dos filhos. Recuperando a proposta de dona Guilherma de que se construa um espaço de apoio mútuo, seu Joaquim busca dissolver a tensão instaurada.

Joaquim - (...) se nós começar a brigar assim, de gato e rato (...) Responsabilidade, que nós tudo tem! (...) de pegar o encargo da familia! (...) tratar esses filho (...) dar tudo de bom prá eles (...)

Joaquim-voz-paterna intervém na disputa, oferecendo-se como exemplo de como construir bons relacionamentos familiares. Os participantes passam a se construir na arena dos relacionamentos familiares, produzidos como cenários fundamentais para a qualidade de vida no envelhecimento.

É provável que a centralidade que a família vai ocupando se articule à forma como, segundo Debert (1999), os relacionamentos familiares vinham, até o final da década de 60, ocupando lugar de destaque, no discurso gerontológico em geral, como fundamentais para a velhice bem-sucedida.

Ainda que estudos recentes problematizem esta noção, pode-se considerar que a forma como a familia vem sendo construída sócio-historicamente, e seu lugar privilegiado enquanto espaço de socialização, palco de tensão e local privilegiado de múltiplos afetos, solidariedades e disputas (Romanelli \& Bezerra, 1999) se articulem à centralidade que a mesma vai assumindo no processo conversacional grupal.

Os participantes se engajam na produção e normatização de descritores, tanto do envelhecimento saudável quanto do não-saudável, inaugurando o que definimos como o terceiro momento do grupo.

\section{Momento 3: A Família Assume a Centralidade}

Tiana- (...).esse negócio de falar assim, nós velho é cri-crí (...) crí-crí vem de nós, esse negócio de nó na cabeça, vem de nós! (...) "nossa aquela senhora num gosta de barulho, de criança (...) gosta de ficar sozinho, quietinho" (...) se a pessoa por a cabeça, conveniar em Deus, pensar, tudo, num chega nesse ponto!

Guilherma- Nós tendo a cabeça no lugar (...) Nóis vai em frente, né!

Tendo por contexto as vivências familiares, nesse momento os interlocutores lançam-se ao movimento de estabelecer negociações em torno de alguns descritores da velhice cri-cri. Esta, não saudável, é construída no espaço de interlocução grupal como aquela em que não se tem a cabeça no lugar e que redunda em isolamento, dificuldade de convivência com os netos-crianças, em perdas, restrições e retrocesso. A velhice cri-cri é construída pelos interlocutores como doença, possessão e responsabilidade individuais, e nessa medida, os mesmus são implicados como individualmente responsáveis pelas possibilidades de bem estar, pelo ir em frente, por um curso ascendente no desenvolvimento.

Tiana- (...) a mocidade, temo tanto conselho, tanta coisa boa prá nóis dá (...)

Guilherma- (...)fim de semana, eu tô num mar de rosas! Prá mim, é a coisa melhor (...) Os filho, os neto (...) satisfação que eu tenho (...)

Mara- (...) minha familia é muito valorizada! (...) num gostava nem de ouvir música! ensinando a gente, coisa que a gente não viveu! (...)'

Os interlocutores articulados na produção de descritores do envelhecimento saudável, o descrevem 


\section{Cesar Sandoval Moreira Jr}

relacionado às possibilidades de negociação e convivência das diferenças, que permitam formas de participação efetiva e prazerosa no contexto familiar.

De acordo com o conceito de envelhecimento primário ou normal, descrito por Neri e Cachioni (1999) como consistindo num processo em que as mudanças físicas progressivas, intrínsecas, universais e irreversíveis do envelhecimento não configuram quadro patológico, os participantes trazem aspectos de seus relacionamentos familiares cotidianos como alvo da conversa no grupo.

Nesse processo dialógico são produzidos como descritores do envelhecimento saudável o senso de utilidade, e a possibilidade de trocas nos relacionamentos familiares. Desfrutar, trocar, dar, e aprender se constituem em descritores que apontam possibilidades de negociação de diferenças no envelhecimento, ausentes na velhice-cri-cri, à qual resta como alternativa, o isolamento, fruto de nó na cabeça, possessão individual.

As descrições acordadas como constituindo perspectivas de um envelhecimento saudável, referem-se, na mesma direção de muitos dos discursos gerontológicos recentes (Debert, 1999; Deps, 1993; Lopes, 2000; Neri, 1999), às possibilidades de convivência e bom relacionamento familiar e social, o que diminui a sensação e os efeitos negativos do isolamento, eleva a auto-estima, o senso de autonomia, e de bem estar.

Ainda que a possibilidade de envelhecimento saudável se articule às múltiplas possibilidades interacionais do contexto familiar, continua sendo produzida como responsabilidade individual, na medida que é descrita como produto da forma como os participantes se constroem individualmente neste contexto. A temporalidade, ao início do grupo remetida às ações do tempo no corpo, é reconfigurada ao presente dos relacionamentos no aqui-agora grupal e no contexto familiar.

Não se reconhecendo em algumas descrições acordadas como necessárias à qualidade de vida na velhice, dona Hermosa passa a demandar ajuda, uma demanda produzida no relacionamento grupal, que gera tensões e mudanças nas interações, ajudando a produzir o que delimitamos como quarto momento conversacional.

\section{Momento 4: Quando a Família Fracassa}

Hermosa- (...) meu problema, eu tenho vergonha de dizer! (...) sinto envergonhada diante de tanta coisa bonita que eu acabei ouvindo aqui!(...) fico nervosa demais (...) num sei se eu devo ter algum problema! (...) de cabeça, nervosia, ou alguma coisa que eu preciso tratar com um médico, um neurologista...ou se eu preciso de uma religião (...) num consigo, às vezes entender nem eu! (...) Sem querer eu me descontrolo! (...)

Dóna Hermosa-problemática-envergonhada muda o tom com que a conversa vinha se dando. $\mathrm{Pa}-$ rece ser em relação aos descritores do idoso saudável produzidos e negociados no grupo, que dona Hermosa cri-cri se constró neste momento.

A possibilidade de qualidade de vida no envelhecimento se articula a certos padrões de convivência familiar que pressupõem diálogo e negociação em torno das diferenças, que resultam em possibilidades de relacionamentos em certa medida prazerosos, redundando em senso de utilidade (ajudar, dar), trocas, desfrute ou aprendizagem nos mesmos.

Construindo uma versão de si mesma a partir destes sentidos produzidos e contrapondo-se aos mesmos, Dona Hermosa-descontrolada-agressiva se sente envergonhada diante de tanta coisa bonita com que teve contato no espaço de interlocução grupal. Em contraposição a tanta coisa bonita, dona Hermosa se sente feia, envergonhada.

Nesse quarto momento, a partir dessa tensão instaurada por dona Hermosa, - que vai se descrever como tendo os atributos individuais negociados como imprescindíveis ao envelhecimento saudável mas também como não contando com o suporte familiar necessário para tal - os participantes se organizam em torno de sua demanda por ajuda e das possibilidades de apoio. Dona Hermosa-problemática-doentedesviante passa a demandar ajuda, contando suas inúmeras dificuldades na relação com o marido e gerando tensões e mudanças nas interações. Os outros participantes buscam explorar alternativas tranquiilizá-la. 
Hermosa-Que nem o meu marido, a gente nota que ele tá com aquele ódio de mim (...)

Joaquim- (aconselhando) Aquele mal pensamento já foi prá senhora (...) é como eletricidade (...) o que é bom vem, o que é mal, avoa, né!

Mário- (...) coitada! (...) é um convívio dificil! A senhora, prá conseguir vencer, formação espiritual boa, tem que sê forte, senão desorienta (...)

No movimento do grupo dona Hermosa vai sendo reconstruída como alguém que deve ser fortesaudável para suportar os efeitos do seu contexto relacional familiar, reconstruído como doente.

Se até então, na conversa grupal, as possibilidades de qualidade de vida pressupunham responsabilidades e atributos individuais, se desenham mais nitidamente agora as implicações dos contextos sócio-interacionais para o envelhecimento saudável.

Pode-se apontar movimento semelhante no campo da Gerontologia, quando de responsabilidade e vivência individual, o envelhecimento vai sendo reconstruído numa perspectiva sócio-histórica (Neri, 1999). A partir desta situação se vê problematizada a noção de velhice saudável como responsabilidade individual, na medida que não basta simplesmente querer ou contar com as possibilidades pessoais descritas como fundamentais para a qualidade de vida, devese contar também, necessariamente, com um contexto favorável para tal.

$\mathrm{Na}$ conversa grupal, buscando alternativas a quem não conte com a família como apoio-suporte, os participantes se envolvem na busca de contextos extra-familiares potencialmente favoráveis ao bemestar, ganhando importância outros espaços relacionais, como a igreja e o grupo de sala de espera, instaurando o que construímos como o quinto e último momento do grupo.

Momento 5: O que Ainda Resta de Vida?

Hermosa- (...) conversando com as pessoa...eu sinto melhor!(...)

Joaquim- (...) igual essa reunião (...) quando ela chega em casa, chega mais reforçada! (...) Sente um ambiente bom, leva de casa, prá dentro! (...) Porque a senhora ouviu muitas coisa boa (...) então é ir guardando de memória! Colhendo aquilo que é bom! (...)

Hermosa- Eu falo prá ele, "eu vou na igreja, vão na igreja procê ouví a palavra de Deus", (...)

Joaquim- (...) essas passagens que a senhora traz, da igreja, e tal, que a senhora vai lá, a senhora já leva prá casa!(...) Que a senhora vai buscar! Recebendo e levando com a senhora, é coisa muito linda! Agora se a senhora abandonar (...) aí a coisa complicada!

Na medida que não se conte com um espaço familiar adequado e diante das dificuldades na construção do mesmo, da falta de tempo, e da urgência que este assume nas descrições sobre o envelhecimento, deve-se buscar outros espaços favoráveis às possibilidades de bem-estar na velhice. $O$ grupo de sala de espera e a igreja são construídos como contextos em que dona Hermosa-saudável se sente melhor e onde pode buscar reforço e apoio no enfrentamento das dificuldades familiares.

O discurso gerontológico tem enfatizado a importância dos relacionamentos sociais e grupais, concebendo-os como favoráveis à qualidade de vida no envelhecimento, na medida que favoreçam trocas de experiência e significados em comum, que possibilitem expressão afetiva, suporte, apoio, compreensão, redução do stress, bem estar emocional e auto-con- 
ceito positivo (Deps, 1993).

Joaquim- A gente se encontra satisfeito! (...) essa reuniãozinha é tão bão! A gente sente muita paz (...) é o dever nosso! Proteger o nosso tempo! Que o tempo tá duro, vamo aproveitar o tempo! (...) cada um de nós tamo caminhando um pouquinho do barco, né! (...) vamo procurar sempre equilibrar o barco no canto certo! Porque no tempo que nós tá, se nós desequilibrar ele, pronto, como que faz agora?! O tempo tá pôco!? Então vamo equilibrá ele no caminho certo! (...) tamo colhendo, e quando nós chegamo lá fora (...) que a gente sente que ofende, a gente tem esse reforço prá evitar aquele momento! (...) outra hora que eu estiver cá, e estiver no jeito, eu quero tá colhendo, tá participando...até nóis levá o barco, porque se o barco desviar, depois é duro tocar prá frente!'

A participação no grupo se configura como possibilidade de construção de apoio, assumindo uma função preventiva, evitando o desviar do barco, garantia das possibilidades de desenvolvimento. Os interlocutores passam a considerar a questão da temporalidade no envelhecimento, orientada agora, não às ações do tempo no corpo, e sim às perspectivas presentes e futuras, e à urgência em se aproveitar o tempo de vida que resta.

Assim, a questão da temporalidade que inicialmente focalizava as conseqüências das ações do tempo no corpo e depois foi remetida aos relacionamentos familiares cotidianos do termpo vivido, passa na conversa do grupo a ser orientada às perspectivas presentes e futuras dos participantes.

\section{Considerações finais}

Entre as diversas descrições do envelhecimento humano, produzidas nesse processo conversacional do grupo de sala de espera, em um Ambulatório de Geriatria, podemos destacar as noções de envelhecimento referidas: (1) à busca de cuidados no contexto da atenção saúde e aos tratamentos paliativos e inocuos frente ao inevitável declínio físico, à morte; (2) à atividade, preservação da autonomia, enfrentamento e necessidade de negociação no contexto familiar; (3) ao isolamento, possibilidade de convivência com as diferenças, dar-ajudar, trocar, desfrutar, aprender nos relacionamentos; e (4) à possibilidade de busca de qualidade de vida em outros contextos relacionais.

Essa análise buscou dar visibilidade a dois aspectos desse processo de produção de sentidos no contexto do grupo:

- a ampliação das descrições do envelhecimento como possibilidade de vida, à medida que os participantes foram se reconstruindo discursivamente como capazes de ações e atitudes relacionais em direção a um envelhecimento saudável; e

- a progressiva incorporação dos aspectos sóciointeracionais nas descrições das possibilidades de qualidade de vida no transcorrer do processo de envelhecimento. De responsabilidade exclusivamente individual, a perspectiva de um envelhecimento saudável vai sendo reconfigurada aos contextos sócio-interacionais dos participantes.

Pode-se considerar que tanto a desnaturalização do envelhecimento, tal como produzido a partir da perspectiva individualizante, quanto o interesse na busca de qualidade de vida na idade madura, constituam-se em direções também recentemente presentes no campo da Gerontologia.

Entendemos, como apontam Spink e Medrado (1999) que a construção destes sentidos teve por base os vários discursos sociais que informam o processo de envelhecimento - os sentidos forjados no tempo histórico, que compõem as redes coletivas de significado; as possibilidades de interjogo entre as experiências do tempo vivido - tempo da memória afetiva da socialização e aprendizagem, e o tempo curto da interação, do aqui-agora do grupo engendrado pela sua configuração específica - que suscitou a possibilidade desses sentidos e não outros.

Operando a partir das possibilidades sociais de construção do envelhecimento via apropriação e uso dos seus sentidos e discursos sociais, os sentidos foram sendo reconstruídos na descrição de vivências dos participantes. Foi no interjogo entre a sustentação das descrições hegemônicas dotadas de maior permanência social e pessoal e a construção de formas descritivas singulares, que se produziram algu- 
mas das possibilidades transformadoras.

Se, de acordo com uma perspectiva contemporânea já apontada na literatura científica, o processo de envelhecimento se constitui em experiência heterogênea e não universal (Debert, 1999; Lopes, 2000), os participantes, ao conversarem, produziram, de acordo com as vicissitudes relacionais existentes e com os repertórios e discursos sociais sobre o envelhecimento humano, possibilidades dialógicas de troca, de interação e de construção e reconstrução dos sentidos e selves. Favorecer que as pessoas se coloquem nestes processos se configura, a nosso ver, como uma das metas do fazer psicológico no contexto da atenção em saúde.

Uma das implicações da adoção do referencial sócio-construcionista na construção de sentidos sobre o grupo de sala de espera em Ambulatório de Geriatria, foi remetê-lo ao processo do conversar, suscitando a questão relativa à especificidade dessa conversa no conjunto dos outras conversas da vida cotidiana.

Entendemos que a especificidade desse conversar dos participantes - mediado por um psicólogo / profissional de saúde, numa sala de espera de uma instituição de saúde - é exatamente favorecer que, em coerência ao contexto em que a conversa ocorre, o sentido do conversar seja também construído em relação a uma ação concreta de promoção de saúde.

$\mathrm{Na}$ medida que o ato de conversar possa ser também significado como busca ativa de saúde, em coerência às diretrizes da reforma sanitária, os participantes podem se co-construírem como ativos na produção da qualidade de vida, abrindo-se ainda a perspectiva de que esta ação, focada nas instituições especializadas, possa se potencializar em outros espaços de convivência.

\section{Referências Bibliográficas}

Barros, R.B. (1994). Grupo: A Afirmação de um Simulacro. Tese de Doutorado, PUC-SP.

Beauvoir, S. (1990). A Velhice. Rio de Janeiro: Nova Fronteira.

Brasil / Ministério da Saúde (1997). Diretrizes e Normas Regulamentadoras de Pesquisa Envolvendo Seres Humanos. Brasília: Conselho
Nacional de Ética em Pesquisa.

Brasil / Ministério da Justiça (1998). Política Nacional do Idoso - Declaração Universal dos Diretos Humanos. Brasília: Secretaria Nacional dos Diretos Humanos.

Camarano, A.A., Bestrão, K.I., Pascom A.R.P., Medeiros, M., Carneiro I.G., Goldani, A.M., Vasconcelos, A.M.G., Chagas, A.M.R. \& Osório, G. (2000). Como Vai o Idoso Brasileiro? Texto para Discussão, $n^{\circ} 681$. IPEA. Rio de Janeiro.

Costa, E.M.S. (1998). Gerontodrama: a velhice em cena: estudos clínicos e psicodramáticos sobre a terceira idade. São Paulo: Agora.

Debert, G.G. (1999). A Construção e a Reconstrução da Velhice: Família, Classe Social e Etnicidade. Em A.L. Néri \& G.G.Debert. (Org), Velhice e Sociedade (pp.41-68). Campinas: Papirus Coleção Vivaidade.

Deps, V.L. (1993). Atividade e bem-estar psicológico na maturidade. Em A.L. Neri (Org), Qualidade de Vida e ldade Madura (pp. 57 - 82) Campinas: Papirus.

Gergen, K.J. (1997). Realitties and Realionship: soundings in social construction. Cambridge: Harvard Univerity Press.

Lane, S.T. (1994). O processo grupal. Em S. Lane \& W. Codo (Orgs.), Psicologia social. O homem em movimento. São Paulo: Brasiliense.

Lima, A.M.D. (1996). Saúde no Envelhecimento: O Discurso Sanitário dos Programas de Saúde. Dissertação de Mestrado. Faculdade de Medicina- USP.

Lledo, R., Herver, P., Garcia, A., Guel, J., Setoain, J. \& Asenjo, M. A. (1995). Information as a fundamental atribute among outpatients attending the nuclear medicine service of a university hospital. Nucl Med Commun., 16 (02) , 76-83.

Lo Biando, A.C., Bastos, A.V.B., Nunes, M.L.T. \& Silva, R.C. (1994). Concepções e atividades emergentes na psicologia clínica: implicações para a formação. Em R. Achcar (Org.), Picólogo Brasileiro: práticas emergentes e desafios 


\section{Cesar Sandoval Moreira $\mathrm{Jr}$}

para a formação (pp. 07-80). São Paulo: Casa do Psicólogo.

Lopes, A. (2000). Os desafios da Gerontologia no Brasil. Campinas: Editora Alinea.

Minois, G. (1997). História de la vejez. De la antiguidade al renascimento. Madrid: Editorial Nerea S.A.

Moreira Jr., C.S.M. (2001). Grupo de Sala de Espera em Ambulatório de Geriatria: a produção de sentidos sobre o envelhecimento humano. Dissertação de mestrado em Psicologia, FFCLRPUSP.

Neme, C.M.B. \& Pícaro, I.M. (1992). Estratégia de Pré-Atendimento: Grupos de Espera em Atendimento Psicológico Infantil em Serviço de Saúde Mental. Anais do II CONPSIC. II Congresso de Psicologia, Conselho Regional de Psicologia, 6 Região, 300-302. São Paulo: Oboré.

Neri, A.L. (1993). Qualidade de Vida no Adulto Maduro: Interpretações Teóricas e Evidências de Pesquisa. Em A.L. Neri (Org), Qualidade de Vida e Idade Madura (pp. 9-53) Campinas: Papirus.

Neri, A.L. \& Cachioni, M. (1999). Velhice BemSucedida e Educação. Em A.L Néri \& G.G. Debert (Orgs.), Velhice e Sociedade (pp. 113140) Campinas: Papirus - Coleção Vivaidade.

Neri, A.L. (1999). Apresentação. Em A.L Néri \& G.G. Debert (Org.), Velhice e Sociedade (pp. 7-10) Campinas: Papirus - Coleção Vivaidade.

Pérez, E.R. (1997). Grupos e Intervenções Grupais: Concepções, Relações e Implicações na Perspectiva de Profissionais que Trabalham com Grupos. Dissertação de Mestrado em Psicologia Social, PUC-SP.

Poulsen, K.A. \& Jacobson, L. (1994). Quality development at an emergency unit - et intervention study based on consumer satisfaction. Ugeskr Leager, 156 (35), 4962-5.

Romanelli G. \& Bezerra, N.M.A. (1999). Estratégias de sobrevivência em famílias de trabalhadores rurais. Paidéia - Cadernos de Psicologia e
Educação, 9, (16), 77-87.

Schouri, P.C.L., Szajnbock, M. (1993). Grupo de espera - Uma nova perspectiva de abordagem institucional._Revista Brasileira de Psiqiatria, 42 (04) 215-217.

Spink, M.J. \& Frezza, R.M. (1999). Práticas Discursivas e Produção de Sentidos: a perspectiva da Psicologia Social. Em M.J. Spink (Org), Práticas discursivas e Produção de Sentidos no Cotidiano - aproximações teóricas e metodológicas (pp.17-49). São Paulo: Cortez.

Spink, M.J. \& Medrado, B. (1999). Produção de sentidos no cotidiano: Uma abordagem teóricometodológica para análise das práticas discursivas. Em M.J. Spink (Org.) Práticas discursivas e Produção de Sentidos no Cotidiano - aproximações teóricas $e$ metodológicas (pp.41- 62). São Paulo: Cortez.

Spink, M.J. \& Menegon, V.L. (1999). A Pesquisa como Prática Discursiva: superando os horrores metodológicos. Em M.J. Spink (Org), Práticas discursivas e Produção de Sentidos no Cotidiano - aproximações teóricas $e$ metodológicas (pp. 63-92). São Paulo: Cortez.

Zaspe, C., Margall, M.A. Otano, C., Perochena, M.P. \& Asian, M.C. (1997). Meeting needs of family members of critically ill patients in a Spanish intensive care unit. Intensive Crit Care Nurs, $13(01), 6-12$.

Trabalho derivado da Dissertação de Mestrado de Cesar Sandoval Moreira Jr. Trabalho apresentado no V Seminário de Pesquisa realizado pelo Programa de Pós-Graduação em Psicologia da FFCLRP-USP, em 2002. 